\title{
Verbal Aggressiveness and Affective Learning in Physical Education
}

\author{
Alexandra Bekiari, Theodota Tsaggopoulou \\ Faculty of Physical Education and Sports Science, University of Thessaly, Trikala, Greece \\ Email: sandrab@pe.uth.gr
}

How to cite this paper: Bekiari, A., \& Tsaggopoulou, T. (2016). Verbal Aggressiveness and Affective Learning in Physical Education. Advances in Physical Education, 6, 406-418.

http://dx.doi.org/10.4236/ape.2016.64041

Received: October 28, 2016

Accepted: November 20, 2016

Published: November 23, 2016

Copyright $\odot 2016$ by authors and Scientific Research Publishing Inc. This work is licensed under the Creative Commons Attribution International License (CC BY 4.0).

http://creativecommons.org/licenses/by/4.0/

\begin{abstract}
In this study, relations among physical education instructors' verbal aggressiveness were examined as perceived by students and students' affective learning. The sample consisted of 297 students (approx. 50\% males and 50\% females) aged 9 - 12 years old $(M=11.2, S D=0.68)$ from primary schools who completed two types of questionnaires during physical education classes. Statistically significant differences were observed in affect towards recommended course behavior between the two genders of the students. ANOVA's findings supported that there was a significant dependence between classes on the factors of affect towards course content and affect towards recommended course behavior. Correlational analysis indicated that perceived instructors' verbal aggressiveness was negatively related to affect towards course content, affect towards recommended course behavior and affect towards the instructor. The results of regression analysis revealed that perceived instructors' verbal aggressiveness could significantly predict the variables of affect towards the instructor. Distinct types of students are also proposed: 1) the "full affected" and 2) the "behaviorally affected" student.
\end{abstract}

\section{Keywords}

Verbal Aggressiveness, Affective Learning, Physical Education

\section{Introduction}

\subsection{Verbal Aggressiveness}

The education system is one of the main areas where communication and interaction between students and teachers can be achieved (Bekiari \& Hasanagas, 2016a; 2016b). The way teachers communicate in the classroom with their students, has a great impact in the learning process and course-related behavior that takes place in the classroom (Haleta, 1996; Richmond \& Gorham, 1996). Infante (1987) argued that during commu- 
nication of people there are four traits of aggressive behavior: assertiveness, hostility, argumentativeness and verbal aggressiveness. Verbal aggressiveness is defined as the attack of a person to others' self-perception in order to cause them psychological pain, such as humiliation, shame, depression, helplessness, despair, along with more negative feelings about themselves (Infante \& Wigley, 1986). Additionally, verbal aggressiveness of a person can be expressed in the ten following forms: attack to one's character, abilities, external appearance and background, mockery, threats, profanity, cursing, vexing behavior and offensive gestures (Infante, Sabourin, Rudd, \& Shannon, 1990; Infante 1987; Infante, Riddle, Horvath, \& Tumlin, 1992). Manifestation of verbal aggression is the result of one's personality, as well as the conditions of the social environment where he/she acts, as it aims more at the persons' self-perception than their opinions on the topic (Infante \& Rancer, 1996). The majority of research shows that verbal aggression is considered a destructive feature in communication (Bekiari, 2016; Bekiari \& Manoli, 2016; Bekiari \& Syrmpas, 2015; Infante, 1995; Manoli \& Bekiari, 2015; Myers \& Rocca, 2000a; Myers et al., 2007). It was found that there is a negative relation between the perceived verbal aggressiveness of the teacher and the affective learning concerning the content of the course, the conduct of the teacher in class and in terms of the recommended behavior (Bekiari, 2012; Myers \& Knox, 1999; 2000a, 2000b; Myers \& Rocca, 2000b; 2001), regarding the intrinsic motivation of students, as well as the reasons for discipline in class (Bekiari, Kokaridas, \& Sakellariou, 2006; Bekiari \& Tsiana, 2016). In addition, there was found that increased levels of verbal aggression of physical education teachers lead students in cognitive loss in the course, which affects the learning process, reducing students' satisfaction and intrinsic motivation (Bekiari, 2014; Bekiari \& Sakellariou, 2003; Bekiari, Kokaridas, \& Sakellariou, 2005; Bekiari, Perkos \& Gerodimos, 2015). Moreover, it was found that the perceived teacher verbal aggressiveness has a negative correlation with student interpersonal attraction (Myers \& Johnson, 2003; Avtgis \& Rancer, 2008; Syrmpas \& Bekiari, 2015) teacher reliability (Schrodt, 2003; Mazer \& Hunt, 2008; Schrodt \& Finn, 2010; Mazer \& Stowe, 2015) and student fair play behaviors (Hassandra, Bekiari \& Sakellariou, 2007) and anxiety in non-contact and high-contact sports (Bekiari, Digelidis, \& Sakellariou, 2006; Bekiari, Patsiaouras, Kokaridas, \& Sakellariou, 2006; Huang, Cherek, \& Lane, 1999; Lemieux, McKelvie, \& Stout, 2002).

\subsection{Affective Learning}

Affective domain of learning is related to values, attitudes and behaviors. It includes the ability of a person to listen, respond to others, demonstrate appropriate behaviors and attitudes, maintain balances and show interest, as well as to be consistent on a daily basis, and at the same time willing to reconsider his opinions and changes the behavior suitably whenever new situations occur (Shephard, 2008). Students' motivation and their emotional state is also evidence of affective learning (Beard et al., 2007). Therefore, affective learning concerns the sentimental area of learning which reflects upon the students' beliefs, values, interests and behaviors (Krathwohl et al., 1964; Smith \& 
Ragan, 1999; Gronlund \& Brookhart, 2009). Affective learning is the main mediating factor between the teacher's immediacy and cognitive learning. More specifically, communicatory variables of teachers such as immediacy, self-confidence, responsibility, homophily, attractiveness lead students to acquire or increase their positive attitude towards the course, appreciate and give more value and emphasis to their tasks, and consequently achieve cognitive learning (Rodríguez, Plax, \& Kearney, 1996; Comadena, Hunt, \& Simonds, 2007; Aydin, 2012). Additionally, the teacher's concern, the internal and the external motivation, as well as the goal setting are major factors of affective learning (Weber, Martin, \& Patterson, 2001; Mottet, Richmond, \& McCroskey, 2006). According to Frymier (1994), affection towards the teacher also has a positive impact on learning and affective learning and some strategies for affective learning are more useful than others in the teaching content (e.g. educative films may prove more effective than simple presentation). There was also evidenced that the teacher's communicational behaviors have an effect on students' affective learning (Mottet et al., 2008) while increased immediacy of the teacher is associated with increased affective learning (McCroskey, Fayer, Richmond, Sallinen, \& Barraclough, 1996). There was found that the perceived low verbal aggressiveness of the teacher and the high interest in the students show a positive correlation with their affective learning, motivation, cognitive learning and satisfaction (Myers, 2002; Infante, 1995; Wanzer \& McCroskey, 1998).

\subsection{The Present Study}

This study aims at examining the relations among perceived instructors' verbal aggressiveness and affective learning during physical education lessons in primary schools.

In particular, this study intends to answer the following research questions:

- Are there any differences noted between the sexes and classes regarding verbal aggressiveness and affective learning?

- Is there a positive or negative relationship between instructors' verbal aggressiveness as perceived by students with students' self-reports of affective learning in physical education classes?

- To what extent the perceived instructors' verbal aggressiveness could be a significant predictor of students' affective learning?

- Can a students' typology regarding parameters of verbal aggressiveness perception and affective learning be extracted?

\section{Method}

\subsection{Participants and Procedures}

The participants of the study were 297 Greek students ( 149 males and 147 females-one of the interviewees did reveal gender), 9 - 12 years old, $(M=11.2, S D=0.68)$ stemming from primary schools of Kastoria, Greece. All the participants were between the $4^{\text {nd }}$ grade (108 students), $5^{\text {th }}$ grade (92 students) and $6^{\text {th }}$ grade (97 students) of six public primary schools and belonged to different socio-economic status. The participants answered two questionnaires referring to the physical education instructors' verbal ag- 
gressiveness and students' affective learning. The completion of questionnaires lasted for 20 - 30 minutes approximately, while the whole process flowed smoothly. The informants participated anonymously and voluntarily. In this way, it is supposed to obtain sincere answers. Best practice rules and research ethics were observed.

\subsection{Instruments}

Verbal aggressiveness. The Greek version (Bekiari \& Digelidis, 2015), which was used to assess instructors' verbal aggressiveness, was based on Infante and Wigley's Verbal Aggressiveness Questionnaire (1986). Preliminary examination supported the psychometric properties of the instrument (Bekiari \& Digelidis, 2015). More specifically, confirmatory factor analysis showed satisfactory fit indices (CFI: 0.97, SRMR: 0.02), and internal consistency of the scale $(\alpha=0.96)$. The scale included eight items (e.g., "the teacher is rude", "the teacher makes students feel uncomfortable"). A 5-point Likerttype scale was used ranging from 1: Strongly disagree to 5: Strongly agree.

Affective learning. The Greek version (Bekiari, 2012), which was used to assess students' affective learning, was based on McCroskey's Affective Learning Measure (1994) and a later revision by Mottet and Richmond (1998). Preliminary examination (Bekiari, 2012) supported the psychometric properties of the instrument. In particular, confirmatory factor analysis indicated satisfactory fit indices (CFI: 0.96, SRMR: 0.05) and internal consistency of the scale (Cronbach's alpha ranged from 0.80 to 0.95 ). The scale consisted of 14 items and three factors: affect towards course content (4 items, e.g. "I believe that the module is useful"), affect towards recommended course behavior (5 items, e.g. "in my daily life I can use information obtained by the module"), and affect towards the instructor ( 5 items, e.g. "I have a positive opinion of the teacher of this module"). Participants were asked to indicate their agreement with the statements on a 5-point Likert scale with anchors of 1: Strongly disagree and 5: Strongly agree.

\subsection{Data Analysis}

Data analysis included the use of the Statistical Package for Social Sciences (SPSS 21.0). The $\mathrm{t}$-test for independent samples was used in order to reveal statistical significant differences between the two genders of the students. The one-way ANOVA was used in order to reveal statistical significant differences between classes.The Pearson correlation coefficient was used to measure the correlation between the subscales of the questionnaires.Regression analysis was conducted in order to explore the extent to which the perceived instructors' verbal aggressiveness could be a significant predictor of students' affective learning. Principal component analysis was used to formulate a students' typology regarding parameters of verbal aggressiveness perception and affective learning. The level of statistical significance was set at 0.05 .

\section{Results}

Statistically significant differences were observed in students' affect towards recommended course behavior $\left(t_{1294}=-1.99, p<0.05\right)$, while there were no differences be- 
tween gender in instructors' verbal aggressiveness ( $t_{1294}=-0.87, p=0.38$ ), affect towards course content $\left(t_{1294}=-0.90, p=0.37\right)$ and affect towards the instructor $\left(t_{1294}=-1.59\right.$, $p=0.11$ ) between the two genders of the students (Table 1 ).

ANOVA's findings supported that there was a significant dependence between classes on the factors of affect towards course content $\left(F_{2220}=2.04, p<0.05\right)$ and affect towards recommended course behavior $\left(F_{2220}=3.62, p<0.05\right)$ between primary schools in $4^{\text {nd }}, 5^{\text {th }}$ and $6^{\text {th }}$ class (Table 2), while were no differences between schools in verbal aggressiveness $\left(F_{2220}=1.05, p=0.35\right)$ and affect towards the instructor $\left(F_{2220}=0.88, p=\right.$ 0.42 ). Subsequently applied LSD multiple comparison test which showed that the factor of affect towards course content proved to have the higher score on 4 nd class of primary schools compared to 5th and 6th classes and the factor of affect towards recommended course behavior proved to have the higher score on 5th class of primary schools compared to 4 nd and 6 th classes.

A correlation analysis was conducted, the results of which are presented in Table 2. As it can be seen, there was a negative significant relationship between instructors' verbal

Table 1. Students' gender comparison.

\begin{tabular}{|c|c|c|c|c|c|c|c|}
\hline Variables & Gender & $N$ & Mean & $S D$ & $T$ & $\mathrm{df}$ & $p$ \\
\hline \multirow{2}{*}{ Verbal aggressiveness } & Males & 149 & 1.24 & 0.48 & \multirow[b]{2}{*}{-0.87} & \multirow{2}{*}{294} & \multirow{2}{*}{0.384} \\
\hline & Females & 147 & 1.29 & 0.62 & & & \\
\hline \multirow{2}{*}{ Affect_course content } & Males & 149 & 4.37 & 0.43 & \multirow{2}{*}{-0.90} & \multirow{2}{*}{294} & \multirow{2}{*}{0.369} \\
\hline & Females & 147 & 4.42 & 0.52 & & & \\
\hline \multirow{2}{*}{ Affect_course behavior } & Males & 149 & 3.97 & 0.50 & \multirow{2}{*}{-1.99} & \multirow{2}{*}{294} & \multirow{2}{*}{0.048} \\
\hline & Females & 147 & 4.09 & 0.54 & & & \\
\hline \multirow{2}{*}{ Affect_instructor } & Males & 149 & 3.72 & 1.03 & \multirow{2}{*}{-1.59} & \multirow{2}{*}{294} & \multirow{2}{*}{0.113} \\
\hline & Females & 147 & 3.94 & 1.34 & & & \\
\hline
\end{tabular}

Table 2. Students' class comparison.

\begin{tabular}{ccccccc}
\hline Variables & Class & $N$ & Mean & $S D$ & $F$ & $p$ \\
\hline Verbal aggressiveness & $4^{\text {nd }}$ & 108 & 1.18 & 0.29 & & \\
& $5^{\text {th }}$ & 92 & 1.27 & 0.54 & 2.22 & 0.110 \\
Affect_course content & $6^{\text {th }}$ & 97 & 1.35 & 0.74 & & \\
& $4^{\text {nd }}$ & 108 & 4.56 & 0.45 & & \\
& $5^{\text {th }}$ & 92 & 4.33 & 0.43 & 10.16 & 0.000 \\
Affect_course behavior & $6^{\text {th }}$ & 97 & 4.29 & 0.50 & & \\
& $4^{\text {nd }}$ & 108 & 4.06 & 0.57 & & \\
Affect_instructor & $5^{\text {th }}$ & 92 & 4.16 & 0.47 & 6.99 & 0.001 \\
& $6^{\text {th }}$ & 97 & 3.89 & 0.47 & & \\
& $4^{\text {nd }}$ & 108 & 3.92 & 1.33 & & \\
& $5^{\text {th }}$ & 92 & 3.77 & 1.12 & 0.48 & 0.622
\end{tabular}


aggressiveness and affect towards course content $(r=-0.38)$, affect towards recommended course behavior $(r=-0.38)$ and affect towards the instructor $(r=-0.24)$. At the same time, Table 3 presents the Cronbach's alpha, mean scores and standard deviations of the variables.

Moreover, linear regression analyses were conducted to examine the extent to which students' affective learning could be predicted from the ratings of instructors' verbal aggressiveness. The results indicated that perceived instructor verbal aggressiveness could predict significant variance in affective learning $\left(F_{(3293)}=95.37, p<0.001\right)$ with an $\mathrm{R}_{2}$ of $49.4 \%$. Perceived verbal aggressiveness explained $41.6 \%$ of the variance in affect towards the instructor $(\beta=-0.32, t=-14.44, p<0.001)$. The results of the regression analyses are presented in Table 4.

In the Table 5, it is observed that two types emerge: 1) the "full affected" and 2) the "behaviorally affected" student. The former reveals a type of student who is in every way influenced by a non-aggressive instructor. Specifically, such a student seems to be positively stimulated toward lesson content, institutional context of course as well as toward the instructor. On the other hand, a verbally aggressive instructor can mainly achieve the conformity of students to the course rules but not any other affection. Thus,

Table 3. Reliabilities, means, standard deviations and Pearson correlations among variables.

\begin{tabular}{cccccccc}
\hline Factors & $\alpha$ & $M$ & $S D$ & 1 & 2 & 3 \\
\hline 1) Verbal aggressiveness & 0.93 & 1.27 & 0.55 & - & & \\
2) Affect_course content & 0.67 & 4.39 & 0.47 & $-0.37^{* *}$ & - & \\
3) Affect_course behavior & 0.65 & 4.03 & 0.52 & $-0.18^{* *}$ & $0.56^{* *}$ & - \\
4) Affect_instructor & 0.82 & 3.84 & 1.19 & $-0.70^{* *}$ & $0.49^{* *}$ & $0.29^{* *}-$ \\
\hline${ }^{*} p<0.05,{ }^{* *} p<0.001, \alpha=$ Cronbach's alpha. & & & & & &
\end{tabular}

Table 4. Regression analysis results according to verbal aggressiveness.

\begin{tabular}{cccccc}
\hline & $\mathrm{B}$ & $95 \% \mathrm{CI} B$ & $S E$ & $\mathrm{~b}$ & $T$ \\
\hline Affect_course content & -0.07 & $-0.21,0.05$ & 0.06 & -0.08 & -1.21 \\
Affect_course behavior & 0.06 & $-0.04,0.17$ & 0.05 & 0.07 & 1.25 \\
Affect_instructor & -0.69 & $-0.36,-0.27$ & 0.02 & -0.32 & $-14.44^{* *}$ \\
\hline$* p<0.05 * * p<0.001$ & & & &
\end{tabular}

${ }^{\star} p<0.05,{ }^{* *} p<0.001$.

Table 5. Fixed typology.

\begin{tabular}{ccc}
\hline & \multicolumn{2}{c}{ Component } \\
\hline & "Full affected" student & "Behaviorally affected" student \\
\hline Verbal aggressiveness & -0.756 & 0.539 \\
Affect_course content & 0.794 & 0.368 \\
Affect_course behavior & 0.630 & 0.671 \\
Affect_instructor & 0.840 & -0.366
\end{tabular}

Extraction method: principal component analysis. 
the use of verbal aggression seems to achieve immediate but more superficial and restricted effects.

\section{Discussion}

The aim of this study was fourfold: 1) to explore differences between the genders and classes regarding verbal aggressiveness and affective learning, 2) to reveal relationship between perceived instructors' verbal aggressiveness and students' affective learning, 3) to investigate the influence of instructor verbal aggressiveness on student affective learning and 4) to propose students' typology. It was observed that the females proved to have the higher score on students' affect towards recommended course behavior in comparison to males. The $4^{\text {th }}$ class of primary school proved to have the higher score on affect towards course content in comparison to $5^{\text {th }}$ and $6^{\text {th }}$ classes, while the $6^{\text {th }}$ class of primary school the lower score on affect towards recommended course behavior in comparison to $4^{\text {th }}$ and $5^{\text {th }}$ classes. Perceived instructors' verbal aggressiveness was negatively related to affect towards course content, affect towards recommended course behavior and affect towards the instructor. Moreover, perceived instructors' verbal aggressiveness could significantly predict the variables of affect towards the instructor. Distinct types of students are also proposed: 1) the "full affected" and 2) the "behaviorally affected" student.

Previous studies argued that the way in which teachers communicate in the classroom with their students, has a noticeable impact on the learning process and the behavior in the classroom (Haleta, 1996; Richmond \& Gorham, 1996). When the teacher is verbally aggressive, then he may be viewed as "misbehaving" and "inherently hostile" (Infante, 1995) by the students. As a result teacher's verbal aggressiveness was negatively correlated with students' affective learning, as Bekiari (2012) supported in study carried out in university context. In this specific case, it was found that student's affective learning was influenced by teachers' verbal aggressiveness. A large number of studies indicated that teacher's perceived verbal aggressiveness is found to be the most negative predictor of students' affect towards course content, course behavior as well as towards the instructor. Similarly, the outcomes of another study suggested that the perceived verbal aggressiveness of the teacher leads students to show lower liking toward both the course content and the instructor (Wanzer \& McCroskey's, 1998).

Aggressive communication between teachers and students tends to significantly affect learning, behavior, thinking, motivation, socialization and attractiveness (Bekiari \& Hasanagas, 2016c). The findings of this study suggested that there is a negative correlation between verbal aggressiveness and the affect toward the teacher, proving that verbal aggressiveness has great effect on student's attitudes towards teacher and teacher's reliability (Schrodt, 2003; Mazer \& Hunt, 2008; Schrodt \& Finn, 2010; Mazer \& Stowe, 2015). The outcomes of this study are in accordance with previous studies which have proved that verbally aggressive teachers are considered to be less attractive, less competent, less reliable and less appropriate and result to lower levels of perceived teacher immediacy and homophily (Martin, Weber, \& Burant, 1997). A reasonable explanation 
of this could be the fact that the use of verbally aggressive messages such as character attacks, competence attacks, physical appearance attacks, background attacks, malediction, teasing, ridicule, threats, swearing, nonverbal expressions, etc., make students feels embarrassed, humiliated, angry, annoyed, depressed or desperate, and subsequently negatively affected. These feelings are responsible for undesirable classroom climate and for the negative quality of the relationship that the teachers have with their students. A positive classroom climate and a positive relationship with the teacher are important for affection in learning process as the students are more strongly motivated. Moreover, the results of the present study reinforce previous findings (Bekiari, 2012) which indicated that university teachers' verbal aggressiveness leads to negative affect towards the course content.

Previous studies (Myers, 1999) suggested that many verbal behaviors of the teachers' such as immediacy (Gorham, 1988), affinity-seeking strategies (Dolin, 1995; Frymier, 1994), clarity (Sidelinger \& McCroskey, 1997), functional communication skills (Frymier \& Houser, 1998), humor (Gorham \& Christophel, 1992; Wanzer \& Frymier, 1999), verbal receptivity (Robinson, 1993), self-disclosure (Sorensen, 1989), and expression of caring (Teven \& McCroskey, 1997), are positively correlated with students' affective learning.

When teachers are perceived to adopt confirming verbal communication behaviors, students show higher levels of affective learning. Verbal aggression was perceived as irritating, distracting and inherently hostile by the students and led to lower affective learning. This study suggested that students, who are not affected by the teacher, do not enjoy or be interested in the lesson or the course. Therefore, they do not show any positive affective learning outcomes. Students are less likely to develop the basic elements of the affective attitude which consists of the ability to listen, respond to others, demonstrate appropriate behaviors, maintain balances and interest, as well as to be steadily consistent and willing to reconsider teacher's opinions and adapt the behavior suitably whenever new situations occur (Shephard, 2008). The study points out negative impacts of teachers' verbal aggression enhancing findings of other research (Bekiari, 2016; Bekiari et al., 2015; Bekiari \& Manoli, 2016; Bekiari \& Hasanagas, 2015; Infante \& Wigley, 1986; Infante \& Rancer, 1996; Syrmpas \& Bekiari, 2015). Furthermore, the $4^{\text {th }}$ class of primary school proved to be characterized by the higher level of content affect, as many of the students have reached a stimulation stage. The $5^{\text {th }}$ class appears higher score in course behavior, as the students have been adapted to higher level of discipline.

Moreover, two types may be distinguished: 1) the "full affected" and 2) the "behaviorally affected" student. The former reveals a type of student who is in every way influenced by a non-aggressive instructor. Specifically, such a student seems to be positively stimulated toward lesson content, institutional context of the lesson (course) as well as toward the instructor. On the other hand, a verbally aggressive instructor can mainly achieve the conformity of students to the course rules but not any other affection. Thus, the use of verbal aggression seems to achieve immediate but more superficial and restricted effects. Such typologies have been proposed in several analyses (e.g., Bekiari \& 
Hasanagas, 2015; 2016; Bekiari, Hasanagas, Theocharis, Kefalas, \& Vasilou, 2015; Bekiari \& Spyropoulou, 2016; Hasanagas \& Bekiari, 2015; Theoharis \& Bekiari, 2016a, 2016b, 2017) which have also proposed a connection of interpersonal relationships and aggressiveness measured as a structural phenomenon.

The study's findings are in accordance with Infante and Rancer's (1996) suggestion, that the effects of verbal aggression are destructive. Moreover, it has been made clear that the role of teacher's behavior and its importance in cognitive as well as in affective learning is undisputable. For this reason, it is necessary for the teachers to avoid aggressive behaviors, as they bring negative outcomes, and try to develop techniques to control them. Additionally, among the different ways which are used to motivate students and have better learning results, teachers should take seriously the role of affection, as its contribution to cognitive learning. Affective strategies as well as the need to create a positive classroom climate should be considered in learning process in order to promote students' effort, competence, social skills, interest, satisfaction and motivation. Some of the study's limitations are the restricted number of the results and the young age of the students. Another limitation of the study concerned the way of collecting the data, since it raises questions about the reliability of the answers. Future studies may examine larger samples focusing also on the relations of instructors' verbal aggressiveness to students' affective learning or even on different milieus (e.g. family, companionship, professional settings).

\section{References}

Avtgis, T. A., \& Rancer, A. S. (2008). The Relationship between Trait Verbal Aggressiveness and Teacher Burnout Syndrome in K-12 Teachers. Communication Research Reports, 25, 86-89. https://doi.org/10.1080/08824090701831875

Aydin, I. E. (2012). Relationship between Affective Learning, Instructor Attractiveness and Instructor Evaluation in Video Conference-Based Distance Education Courses. Turkish Online Journal of Educational Technology, 11, 247-252.

Beard, C., Clegg, S., \& Smith, K. (2007). Acknowledging the Affective in Higher Education. British Educational Research Journal, 33, 235-252. https://doi.org/10.1080/01411920701208415

Bekiari, A. (2012). Perceptions of Instructors' Verbal Aggressiveness and Physical Education Students' Affective Learning. Perceptual and Motor Skills, 115, 325-335.

https://doi.org/10.2466/06.11.16.PMS.115.4.325-335

Bekiari, A. (2014). Verbal Aggressiveness and Leadership Style of Sports Instructors and Their Relationship with Athletes' Intrinsic Motivation. Creative Education, 5, 114-121. https://doi.org/10.4236/ce.2014.52018

Bekiari, A. (2016). Insights into Instructors' Verbal Aggressiveness and Students' Machiavellianism through Leadership Style and Motivational Climate. European Scientific Journal, 12, 90110. https://doi.org/10.19044/esj.2016.v12n25p90

Bekiari, A., \& Digelidis, N. (2015). Measuring Verbal Aggressiveness in Sport and Education. International Journal of Physical Education, 52, 12-21.

Bekiari, A., \& Hasanagas, N. (2015). Verbal Aggressiveness Exploration through Complete Social Network Analysis: Using Physical Education Students' Class as an Illustration. International Journal of Social Science Studies, 3, 30-49. https://doi.org/10.11114/ijsss.v3i3.729 
Bekiari, A., \& Hasanagas, N. (2016a). Sociological Insights in the Education System: "Unlocking" the Power Relations. Thessaloniki: Afoi Kyriakidi Editions S.A.

Bekiari, A., \& Hasanagas, N. (2016b). “Educating” in Physical Education. Theoretical Approaches and Practical Inquiries. Thessaloniki: Afoi Kyriakidi Editions SA.

Bekiari, A., \& Hasanagas, N. (2016c). Suggesting Indicators of Superficiality and Purity in Verbal Aggressiveness. An Application in Adult Education Class Networks of Prisoners. Open Journal of Social Sciences, 4, 279-292. https://doi.org/10.4236/jss.2016.43035

Bekiari, A., \& Manoli, P. (2016). EFL Teacher Verbal Aggressiveness and Argumentativeness and Student Socio-Affective Strategy Use and Affective Learning: Exploring Possible Associations. Journal of Teacher Education and Educators, 5, 154-171.

Bekiari, A., \& Sakellariou, K. (2003). Perceived Instructor Verbal Aggressiveness and Student State Learning in Physical Education. Italian Journal of Sport Sciences, 1, 251-256.

Bekiari, A., \& Spyropoulou, S. (2016). Exploration of Verbal Aggressiveness and Interpersonal Attraction through Social Network Analysis: Using University Physical Education Class as an Illustration. Open Journal of Social Sciences, 4, 145-155. https://doi.org/10.4236/jss.2016.46016

Bekiari, A., \& Syrmpas, I. (2015). Coaches' Verbal Aggressiveness and Motivational Climate as Predictors of Athletes' Satisfaction. British Journal of Education, Society \&Behavioural Science, 9, 318-329. https://doi.org/10.9734/BJESBS/2015/17757

Bekiari, A., \& Tsiana, I. (2016). Exploring Instructors' Verbal Aggressiveness and Students' Personal Orientations and Reasons of Discipline in Physical Education Class. Advances in Physical Education, 6, 158-168. https://doi.org/10.4236/ape.2016.63018

Bekiari, A., Digelidis, N., \& Sakellariou, K. (2006). Perceived Verbal Aggressiveness of Coaches in Volleyball and Basketball: A Preliminary Study. Psychological Reports, 103, 526-530. https://doi.org/10.2466/pms.103.2.526-530

Bekiari, A., Kokaridas, D., \& Sakellariou, K. (2005). Verbal Aggressiveness of Physical Education Teachers and Students' Self-Reports of Behaviour. Psychological Reports, 96, 493-498. https://doi.org/10.2466/pr0.96.2.493-498

Bekiari, A., Kokaridas, D., \& Sakellariou, K. (2006). Associations of Students' Self-Reports of Their Teacher'S Verbal Aggression, Intrinsic Motivation, and Perceptions of Reasons for Discipline in Greek Physical Education Classes. Psychological Reports, 98, 451-461.

https://doi.org/10.2466/pr0.98.2.451-461

Bekiari, A., Patsiaouras, A., Kokaridas, D., \& Sakellariou, K. (2006). The Relationship between Verbal Aggressiveness and State Anxiety in Volleyball. Psychological Reports, 99, 630-634.

Bekiari, A., Perkos, S., \& Gerodimos, V. (2015). Verbal Aggression in Basketball: Perceived Coach Use and Athlete Intrinsic and Extrinsic Motivation. Journal of Physical Education and Sport, $15,96-102$.

Bekiari, A., Hasanagas, N., Theoharis, D., Kefalas, I., \& Vasilou, A. (2015). The Role of Mathematical Object and the Educational Environment to Students' Interpersonal Relationships: An Application of Full Social Network Analysis. Proceedings of the 32nd Congress Greek Mathematical Society (With International Participation), 799-812.

Comadena, M. E., Hunt, S. K., \& Simonds, C. J. (2007). The Effects of Teacher Clarity, Nonverbal Immediacy, and Caring on Student Motivation, Affective and Cognitive Learning. Communication Research Reports, 24, 241-248. https://doi.org/10.1080/08824090701446617

Dolin, D. J. (1995). Alternative Form of Teacher Affinity-Seeking Measurement. Communication Research Reports, 12, 220-226. https://doi.org/10.1080/08824099509362059

Frymier, A. B. (1994). The Use of Affinity-Seeking in Producing Liking and Learning in the Classroom. Journal of Applied Communication Research, 22, 87-105. 
https://doi.org/10.1080/00909889409365391

Frymier, A. B., \& Houser, M. L. (1998). Using Communication Skills in Teaching and Their Comparison with Immediacy. The Annual Meeting of the Eastern Communication Association.

Gorham, J. (1988). The Relationship between Teacher Immediacy Behaviors and Student Learning. Communication Education, 37, 40-53. https://doi.org/10.1080/03634528809378702

Gorham, J., \& Christophel, D. M. (1992). Students' Perceptions of Teacher Behaviors as Motivating and Demotivating Factors in College Classes. Communication Quarterly, 40, 239-252. https://doi.org/10.1080/01463379209369839

Gronlund, N. E., \& Brookhart, S. M. (2009). Writing Instructional Objectives (8th ed.). Upper Saddle River, NJ: Pearson Education.

Haleta, L. L. (1996). Student Perceptions of Teachers' Use of Language: The Effects of Powerful and Powerless Language on Impression Formation and Uncertainty. Communication Education, 45, 16-39. https://doi.org/10.1080/03634529609379029

Hasanagas, N., \& Bekiari, A. (2015).Depicting Determinants and Effects of Intimacy and Verbal Aggressiveness Target through Social Network Analysis. Sociology Mind, 5, 162-175. https://doi.org/10.4236/sm.2015.53015

Hassandra, M., Bekiari, A., \& Sakellariou, K. (2007). Physical Education Teacher's Verbal Aggression and Student's Fair Play Behaviors. The Physical Educator, 64, 94-101.

Huang, D. B., Cherek, D. R., \& Lane, S. D. (1999). Laboratory Measurement of Aggression in High School Age Athletes: Provocation in a Nonsporting Context. Psychological Reports, 85, 1251-1262. https://doi.org/10.2466/pr0.1999.85.3f.1251

Infante, D. A. (1987). Aggressiveness. In J. C. McCroskey, \& J. A. Daly (Eds.), Personality and Interpersonal Communication (pp. 157-192). Thousand Oaks, CA: Sage.

Infante, D. A. (1995). Teaching Students to Understand and Control Verbal Aggression. Communication Education, 44, 51-63. https://doi.org/10.1080/03634529509378997

Infante, D. A., \& Rancer, A. S. (1996). Argumentativeness and Verbal Aggressiveness: A Review of Recent Theory and Research. Communication Yearbook, 19, 319-352. https://doi.org/10.1080/23808985.1996.11678934

Infante, D. A., \& Wigley, C. J. (1986). Verbal Aggressiveness: An Interpersonal Model and Measure. Communications Monographs, 53, 61-69. https://doi.org/10.1080/03637758609376126

Infante, D. A., Riddle, B. L., Horvath, C. L., \& Tumlin, S. A. (1992). Verbal Aggressiveness: Messages and Reasons. Communication Quarterly, 40, 116-126. https://doi.org/10.1080/01463379209369827

Infante, D. A., Sabourin, T. C., Rudd, J. E., \& Shannon, E. A. (1990). Verbal Aggression in Violent and Nonviolent Marital Disputes. Communication Quarterly, 38, 361-371. https://doi.org/10.1080/01463379009369773

Krathwohl, D. R., Bloom, B. S., \& Masia, B. B. (1964). Taxonomy of Educational Objectives, Handbook II: Affective Domain (The Classification of Educational Goals). New York: David McKay Inc.

Lemieux, P., McKelvie, S. J., \& Stout, D. (2002). Self-Reported Hostile Aggression in Contact Athletes, No Contact Athletes and Non-Athletes. Athletic Insight, 4, 42-56.

Manoli, P., \& Bekiari, A. (2015). EFL Teachers' Verbal Aggressiveness and Students' Intrinsic Motivation and Social-Affective Strategy Use: Investigating Possible Relations. Advances in Research, 5, 1-13. https://doi.org/10.9734/AIR/2015/19692

Martin, M. M., Weber, K., \& Burant, P. A. (1997). Students' Perceptions of a Teacher's Use of Slang and Verbal Aggressiveness in a Lecture: An Experiment. 
Mazer, J. P., \& Hunt, S. K. (2008). The Effects of Instructor Use of Positive and Negative Slang on Student Motivation, Affective Learning, and Classroom Climate. Communication Research Reports, 25, 44-55. https://doi.org/10.1080/08824090701831792

Mazer, J. P., \& Stowe, S. A. (2015). Can Teacher Immediacy Reduce the Impact of Verbal Aggressiveness? Examining Effects on Student Outcomes and Perceptions of Teacher Credibility. Western Journal of Communication, 80, 21-37. https://doi.org/10.1080/10570314.2014.943421

McCroskey, J. C., Sallinen, A., Fayer, J. M., Richmond, V. P., \& Barraclough, R. A. (1996). Nonverbal Immediacy and Cognitive Learning: A Cross-Cultural Investigation. Communication Education, 45, 200-211. https://doi.org/10.1080/03634529609379049

Mottet, T. P., \& Richmond, V. P. (1998). Newer Is Not Necessarily Better: A Re-Examination of Affective Learning Measurement. Communication Research Reports, 15, 370-378. https://doi.org/10.1080/08824099809362136

Mottet, T. P., Garza, R., Beebe, S. A., Houser, M. L., Jurrells, S., \& Furler, L. (2008). Instructional Communication Predictors of Ninth-Grade Students' Affective Learning in Math and Science. Communication Education, 57, 333-355. https://doi.org/10.1080/03634520801989950

Mottet, T. P., Richmond, V. P., \& McCroskey, J. C. (Eds.) (2006). Handbook of Instructional Communication: Rhetorical and Relational Perspectives. Boston, MA: Allyn \& Bacon.

Myers, S. A. (2002). Perceived Aggressive Instructor Communication and Student State Motivation, Learning, and Satisfaction. Communication Reports, 15, 113-121. https://doi.org/10.1080/08934210209367758

Myers, S. A., \& Johnson, A. D. (2003). Verbal Aggression and Liking in Interpersonal Relationships. Communication Research Reports, 20, 90-96. https://doi.org/10.1080/08824090309388803

Myers, S. A., \& Knox, R. L. (1999). Verbal Aggression in the College Classroom: Perceived instructor Use and Student Affective Learning. Communication Quarterly, 47, 33-45. https://doi.org/10.1080/01463379909370122

Myers, S. A., \& Knox, R. L. (2000a). Perceived Instructor Argumentativeness and Verbal Aggressiveness and Student Outcomes. Communication Research Reports, 17, 299-309. https://doi.org/10.1080/08824090009388777

Myers, S. A., \& Knox, R. L. (2000b). The Relationship between Instructor Argumentativeness and Verbal Aggressiveness, and Student State Motivation, Relevance, Affective Learning, and Satisfaction. The Annual Meeting of the Central States Communication Association.

Myers, S. A., \& Rocca, K. A. (2000a). Students' State Motivation and Instructors' Use of Verbally Aggressive Messages. Psychological Reports, 87, 291-294.

https://doi.org/10.2466/pr0.2000.87.1.291

Myers, S. A., \& Rocca, K. A. (2000b). The Relationship between Perceived Instructor Communicator Style, Argumentativeness, and Verbal Aggressiveness. Communication Research Reports, 17, 1-12. https://doi.org/10.1080/08824090009388745

Myers, S. A., \& Rocca, K. A. (2001). Perceived Instructor Argumentativeness and Verbal Aggressiveness in the College Classroom: Effects on Student Perceptions of Climate, Apprehension, and Motivation. Western Journal of Communication, 65, 113-137.

https://doi.org/10.1080/10570310109374696

Myers, S. A., Edwards, C., Wahl, S. T., \& Martin, M. M. (2007). The Relationship between Perceived Instructor Aggressive Communication and College Student Involvement. Communication Education, 56, 495-508. https://doi.org/10.1080/03634520701466398

Richmond, V. P., \& Gorham, J. S. (1996). Communication, Learning, and Affect in Instruction. Edina, MN: Burgess International. 
Robinson, R. Y. (1993). The Usefulness of the Verbal Receptivity Measure in Instructional Communication Research. Communication Quarterly, 41, 292-298.

https://doi.org/10.1080/01463379309369890

Rodríguez, J. I., Plax, T. G., \& Kearney, P. (1996). Clarifying the Relationship between Teacher Nonverbal Immediacy and Student Cognitive Learning: Affective Learning as the Central Causal Mediator. Communication Education, 45, 293-305. https://doi.org/10.1080/03634529609379059

Schrodt, P. (2003). Student Perceptions of Instructor Verbal Aggressiveness: The Influence of Student Verbal Aggressiveness and Self-Esteem. Communication Research Reports, 20, 240 250. https://doi.org/10.1080/08824090309388822

Schrodt, P., \& Finn, A. N. (2010). Reconsidering the Role of Aggressive Communication in Higher Education. In T. A. Avtgis, \& A. S. Rancer (Eds.), Arguments, Aggression, and Conflict: New Directions in Theory and Research (pp. 159-176). New York: Routledge.

Shephard, K. (2008). Higher Education for Sustainability: Seeking Affective Learning Outcomes. International Journal of Sustainability in Higher Education, 9, 87-98. https://doi.org/10.1108/14676370810842201

Sidelinger, R. J., \& McCroskey, J. C. (1997). Communication Correlates of Teacher Clarity in the College Classroom. Communication Research Reports, 14, 1-10. https://doi.org/10.1080/08824099709388640

Smith, P. L., \& Ragan, T. J. (1999). Instructional Design. New York: John Wiley \& Sons Inc.

Sorensen, G. (1989) The Relationships among Teachers' Self-Disclosive Statements, Students' Perceptions, and Affective Learning. Communication Education, 38, 259-276. https://doi.org/10.1080/03634528909378762

Syrmpas, I., \& Bekiari, A. (2015).The Relationship between Perceived Physical Education Teacher's Verbal Aggressiveness and Argumentativeness with Students' Interpersonal Attraction. Inquiries in Sport \& Physical Education, 13, 21-32.

Teven, J. J., \& McCroskey, J. C. (1997). The Relationship of Perceived Teacher Caring with Student Learning and Teacher Evaluation. Communication Education, 46, 1-9. https://doi.org/10.1080/03634529709379069

Theoharis, D., \& Bekiari, A. (2016a). The Influence of Mathematics and Learning Environment in Verbal Aggressiveness and Interpersonal Relations: A Dynamic Analysis of Social Networks. Proceedings of the 8th International Congress Mathematical Society.

Theoharis, D., \& Bekiari, A. (2016b). Analyzing Centrality Indicators of Social Networks. Case Study on Leadership Networks of Students and Teachers. Proceedings of the 33nd Congress Greek Mathematical Society (With International Participation), 250-260.

Theoharis, D., Bekiari, A., \& Koustelios, A. (2017). Exploration of Determinants of Verbal Aggressiveness and Leadership through Network Analysis and Conventional Statistics. Using School Class as an Illustration. Sociology Mind, Forthcoming.

Wanzer, M. B., \& Frymier, A. B. (1999). The Relationship between Student Perceptions of Instructor Humor and Students' Reports of Learning. Communication Education, 48, 48-62. https://doi.org/10.1080/03634529909379152

Wanzer, M. B., \& McCroskey, J. C. (1998). Teacher Socio-Communicative Style as a Correlate of Student Affect toward Teacher and Course Material. Communication Education, 47, 43-52. https://doi.org/10.1080/03634529809379109

Weber, K., Martin, M., \& Patterson, B. (2001). Teacher Behavior, Student Interest and Affective Learning: Putting Theory to Practice. Journal of Applied Communication Research, 29, 71-90. https://doi.org/10.1080/00909880128101 
Submit or recommend next manuscript to SCIRP and we will provide best service for you:

Accepting pre-submission inquiries through Email, Facebook, LinkedIn, Twitter, etc. A wide selection of journals (inclusive of 9 subjects, more than 200 journals)

Providing 24-hour high-quality service

User-friendly online submission system

Fair and swift peer-review system

Efficient typesetting and proofreading procedure

Display of the result of downloads and visits, as well as the number of cited articles

Maximum dissemination of your research work

Submit your manuscript at: http://papersubmission.scirp.org/

Or contact ape@scirp.org 